\title{
DEFICIÊNCIA E DESIGUALDADE SOCIAL: O RECENTE CAMINHO PARA A ESCOLA
}

\author{
Katia Regina Moreno Caiado* \\ Taísa Grasiela Gomes Liduenha Gonçalves ${ }^{* *}$ \\ Rute T. Gaido Telles ${ }^{* * *}$ \\ Ana Carolina Macalli ${ }^{* * *}$
}

\begin{abstract}
RESUMO: Desde a Constituição de 1988, as pessoas com deficiência têm direito a receber um salário mínimo ao comprovarem não possuir meios de prover a própria manutenção - direito regulamentado como Benefício de Prestação Continuada (BPC), em 1993. Em 2007, divulgou-se que $79 \%$ dos beneficiários em idade escolar não frequentavam escola, o que gerou um programa de trabalho interministerial, o BPC na Escola. Em 2010 foi divulgado o Catálogo de Experiências Municipais do Programa BPC na Escola, com relatos de vinte municípios das cinco regiōes do país que implementaram o Programa. O objetivo deste estudo é analisar o impacto do Programa nas matrículas de alunos com necessidades educacionais especiais, nos microdados do Censo Escolar, no período de 2007 a 2012. Os resultados revelam que houve significativo aumento de matrículas de alunos com necessidades educativas especiais, com destaque às matriculas de alunos com deficiência.
\end{abstract}

Palavras-chave: Educação especial. Desigualdade social. Programas sociais.

Centro de Educação e Ciências Humanas da Universidade Federal de São Carlos (Ufscar). São Carlos (SP) - Brasil.

** Programa de Pós-Graduação em Educação Especial (doutoranda) da Universidade Federal de São Carlos (Ufscar). São Carlos (SP) - Brasil.

*** Secretaria Municipal de Educação de Campinas, SP

**** Licenciada em Educação Especial pela Universidade Federal de São Carlos (Ufscar). São Carlos (SP) - Brasil.

Contato com as autoras: <caiado.katia@ufscar.br>

Cad. Cedes, Campinas, v. 34, n. 93, p. 241-260, maio-ago. 2014

Disponível em <http://www.cedes.unicamp.br> 
Deficiência e desigualdade social: o recente caminho para a escola

\title{
DISABILITY AND SOCIAL INEQUALITY: THE NEW PATH TO SCHOOL
}

\begin{abstract}
Since the 1988 Constitution, disabled people are entitled to receive a minimum wage when proving they do not have the means to provide for themselves - this was regulated as a continuous cash benefit (BPC) in 1993. In 2007, it was reported that 79\% of beneficiaries in school age were not attending school. This fact resulted in an interagency work program: BPC at School. In 2010, the Catalog of Municipal Experiences of the BPC at School Program was published, with reports from 20 municipalities (from the five regions of Brazil) that had implemented the program. The objective of this study is to analyze the impact of the Program on the enrollment of students with special educational needs, through the examination of microdata of the School Census from 2007 to 2012 . The results show a significant increase in the enrollment of students with special education needs, with emphasis on the enrollment of students with disabilities.
\end{abstract}

Key words: Special education. Social inequality. Social programs.

\section{Introdução}

história da educação especial no Brasil revela que a condição da deficiência foi, predominantemente, compreendida como um atributo pessoal, marcado num corpo com defeito ou mau funcionamento (JANNUZZI, 2012; LOBO, 2008). Revela também que a maioria dos atendimentos nas áreas da educação e saúde foi responsabilidade da caridade e da filantropia (MESTRINER, 2008; RAFANTE, 2011; JANNUZZI; CAIADO, 2013).

A luta pela conquista dos direitos das pessoas com deficiência em nosso país tem uma história pouco divulgada, mas que revelou sua força e articulação quando o movimento organizado inscreveu seus direitos ao longo de diferentes temas nos capítulos da Constituição de 1988 (LANNA, 2010). A partir desse momento, essa luta ganhou visibilidade no país, ao mesmo tempo em que entrou em rede com os movimentos internacionais - o que impulsionou o Brasil a assumir, recentemente, um novo conceito de deficiência:

Pessoas com deficiência são aquelas que têm impedimentos de longo prazo de natureza física, mental, intelectual ou sensorial, os quais, em 
interação com diversas barreiras, podem obstruir sua participação plena e efetiva na sociedade em igualdades de condiçôes com as demais pessoas. (DECRETO n. 6.949, 2009, art. 10)

Nesse novo conceito, para além de um corpo diverso, a condição da deficiência se revela na interação desse corpo com as barreiras socialmente construídas, que impedem a participação social. Essa perspectiva nos possibilita contrapor os conceitos de diversidade e desigualdade. Pouco se fala sobre a diversidade como condição do que não é igual. Pierucci (1999, p. 47) alertou para essa questão ao afirmar que "a focalização da diferença acaba roubando perigosamente a cena da igualdade". Há pouca produção de conhecimento na área da educação especial que articule deficiência e desigualdades sociais, muito embora recentemente tenhamos falado muito sobre a pobreza e a exclusão - conceitos que, numa leitura crítica, nos remetem às exigências do mercado (SHIROMA; MORAES; EVANGELISTA, 2007).

A intenção maior deste estudo é contribuir para colocar em pauta a discussão sobre as condições concretas de vida de pessoas com deficiência, marcadas pelas profundas desigualdades sociais que assolam o nosso país. São homens e mulheres trabalhadores, na cidade ou no campo, que não conseguem prover a manutenção de suas famílias e sobrevivem da caridade e/ou da assistência social. Essa condição assola milhares de pessoas com deficiência em nosso país. Conhecer essa realidade é ponto de partida para elaborarmos qualquer proposta de superação, seja com medidas imediatas, seja para a construção de um novo projeto de sociedade.

Dados do Instituto Brasileiro de Geografia e Estatística (IBGE) ${ }^{1}$ mostram que a desigualdade social no país em 2012 ainda é cruel: os 40\% mais pobres da população brasileira detêm $13,3 \%$ da renda total do país, enquanto os $10 \%$ mais ricos detêm $41,9 \%$ dessa renda. Sem dúvida, a desigualdade social não se caracteriza apenas na medida da renda. Associados às baixas rendas estão o desemprego, a fome, a falta de moradia e de saneamento, a ausência de serviços de saúde, educação e transporte.

Nesse quadro se colocam os problemas que nos inquietam: quais são as barreiras que têm obstruído a participação plena e efetiva das pessoas com deficiência em nosso desigual país? Com o foco na educação, nos perguntamos: as pessoas com deficiência em idade escolar estão matriculadas na escola? Têm condiçôes de permanecer nela? Têm se apropriado do conhecimento escolar? 
Entende-se que as perguntas sobre a vida das pessoas com deficiência não podem tratar de um sujeito a-histórico. A pessoa com deficiência precisa ser compreendida como sujeito concreto, que vive em determinadas condições sociais, sempre complexas e com múltiplas determinações.

Assim, delimitamos para análise alguns dados de um programa de governo: o Benefício de Prestação Continuada na Escola (BRASIL, Portaria n. 8,2007 )

O objetivo deste estudo é analisar o impacto desse Programa nas matrículas de alunos com necessidades educacionais especiais, nos microdados do Censo Escolar, no período de 2007 a 2012, em vinte municípios que implementaram o Programa.

Para tanto, iniciamos este texto apresentando o Benefício de Prestação Continuada (BRASIL, 1993) e o Programa de Acompanhamento e Monitoramento do Acesso e Permanência na Escola da Pessoa com Deficiência Beneficiária do BPC, o Programa BPC na Escola (BRASIL, 2007). (ibid.). Em seguida, caracterizamos os vinte municípios, das cinco regiōes do país, que implementaram o Programa e socializaram os relatos dessa experiência, divulgados pelo Ministério do Desenvolvimento Social e Combate à Fome (BRASIL, MDS, 2010), apresentando o Índice de Desenvolvimento Humano Municipal (IDHM) e dados referentes à situação escolar e área de moradia desses beneficiários. A área de moradia mostra se os beneficiários residem na área urbana ou rural, sendo que as barreiras existentes no campo para o acesso à escola são enormes no nosso país. Caiado e Meletti (2011) analisam o silêncio que há nas pesquisas em educação especial sobre as pessoas com deficiência que vivem em áreas rurais no Brasil. Caiado e Gonçalves (no prelo) analisam os desafios de transporte escolar para os alunos com necessidades educacionais especiais que vivem no campo.

Com esse quadro, analisamos os microdados do Censo Escolar, referentes às matrículas dos alunos com necessidades educacionais especiais e com a condição de deficiência, nesses vinte municípios, nos anos de 2007 e 2012.

\section{Programa Benefício de Prestação Continuada na Escola}

Desde a Constituição de 1989 as pessoas com deficiência têm direito a receber um salário mínimo ao comprovarem não possuir meios de prover 
a própria manutenção - direito regulamentado como Benefício de Prestação Continuada (BPC), em 1993. ${ }^{2}$

Esse benefício integra o Sistema Único da Assistência Social (Suas), pago pelo governo federal, cuja operacionalização de reconhecimento do direito é do Instituto Nacional do Seguro Social (INSS). Assegurado por lei, permite o acesso de idosos e pessoas com deficiência à proteção social básica com dois campos de atuação: os serviços e os benefícios de caráter pecuniário.

Em 2007 foi realizado o primeiro cruzamento entre bases de dados do Ministério da Previdência Social e do Ministério da Educação. Esse estudo mostrou que entre os 340.536 beneficiários do BPC, pessoas com deficiência na faixa etária de 0 a 18 anos, $100.574(29,53 \%)$ estavam matriculados em escolas, ao passo que $239.962(70,47 \%)$ não tinham registros no sistema regular de ensino. Esse quadro provocou a criação de um Programa de Acompanhamento e Monitoramento do Acesso e Permanência na Escola da Pessoa com Deficiência Beneficiária do BPC, o Programa BPC na Escola (BRASIL, Portaria n. 8, 2007). O Programa envolve o Ministério do Desenvolvimento Social e Combate à fome (MDS), o Ministério da Educação (MEC), o Ministério da Saúde (MS) e a Secretaria de Direitos Humanos da Presidência da República (SEH/PR) e tem como objetivo:

[...] promover a elevação da qualidade de vida e dignidade das pessoas com deficiência beneficiárias do BPC, preferencialmente de 0 a 18 anos de idade, garantindo-lhes acesso e permanência na escola, por meio de ações articuladas da área de saúde, educação, assistência social e direitos humanos. (Ibid.)

O Programa BPC na escola integra o Plano de Desenvolvimento da Educação (PDE) ${ }^{3}$ e o Plano Viver sem Limite (DECRETO n. 7.612, 2011). Este assegura verbas aos municípios e estados que aderirem ao Programa para realização de visitas domiciliares aos beneficiários, visando identificar e superar as barreiras que impedem ou dificultam o acesso e a permanência na escola.

O texto Orientações para implementação da politica de educação especial na perspectiva da educação inclusiva (PREFEITURA MUNICIPAL DE PASSO FUNDO, s/d) traz os seguintes dados em relação aos beneficiários e às matrículas na escola, com base no censo escolar do ano anterior: 
Deficiência e desigualdade social: o recente caminho para a escola

\section{Tabela 1}

Total de beneficiários no Brasil segundo a situação escolar

\begin{tabular}{|cccccc|}
\hline Ano & Total de Beneficiários & Na Escola & \% & Fora da Escola & $\%$ \\
\hline 2007 & 375470 & 75709 & 21 & 278761 & 79 \\
2008 & 370613 & 108426 & 29,25 & 262187 & 70,75 \\
2009 & 401744 & 121688 & 30,28 & 280066 & 69,72 \\
2010 & 435298 & 229017 & 52,61 & 206281 & 47,38 \\
2011 & 445889 & 306371 & 68,71 & 139518 & 31,29 \\
\hline
\end{tabular}

Fonte: Orientaçôes para implementação da política de educação especial na perspectiva da educação inclusiva (PREFEITURA MUNICIPAL DE PASSO FUNDO, s/d).

Apesar da redução no número de beneficiários no Brasil em 2008 $(1,3 \%)$, nos anos posteriores notam-se aumentos sucessivos. Com relação aos beneficiários que frequentavam a escola, os dados indicam que o maior acréscimo ocorreu em 2010, que correspondeu a 88,20\%. No entanto, constata-se que no período de 2007 a 2010 a maioria dos beneficiários encontrava-se fora da escola. Percebe-se que a situação escolar dos beneficiários em nosso país ainda é um desafio. Desse modo, pretende-se analisar experiências de vinte municípios que implementaram o Programa BPC na Escola.

Análise sobre as matrículas escolares de vinte municípios que implementaram o Programa BPC na Escola

Em 2010, o Ministério do Desenvolvimento Social e Combate à Fome (MDS) publicou o Catálogo de Experiências Municipais do Programa BPC na Escola com relatos de vinte municípios que implementaram o Programa, a saber: Cuiabá, Nova Mutum (MT); Goiânia (GO); Barro Alto, Lapão (BA); Acopiara, Quiterianópolis (CE); Nina Rodrigues (MA); Pilóes (PB); Piripiri (PI); Frutuoso Gomes (RN); Porto Velho (RO); Itacajá (TO); Novo Hamburgo (RS); Campo Azul (MG); Campos dos Goytacazes, Nova Iguaçu (RJ); Presidente Prudente, Santo André e São Paulo (SP).

Neste estudo, analisamos dados desses municípios referentes: ao Índice de Desenvolvimento Humano Municipal (IDHM); à situação escolar 
e área de moradia dos beneficiários; às matrículas escolares de alunos com necessidades educativas especiais e com deficiência.

\section{Sobre o Índice de Desenvolvimento Humano Municipal (IDHM)}

O Índice de Desenvolvimento Humano (IDH) é uma medida que reúne três dimensões: longevidade, educação e renda. Essa medida, centrada no desenvolvimento das pessoas, se contrapõe à medida do crescimento econômico, expressa pelo Produto Interno Bruto (PIB) e compreendida como medida de desenvolvimento dos países. Vale destacar que o Brasil, com o IDH de $0,730,{ }^{4}$ ocupou o $85^{\circ}$ lugar na posição entre os demais países (ONU, 2011). ${ }^{5}$

A partir dos dados do Censo Demográfico obtém-se o Índice de Desenvolvimento Humano dos Municípios (IDHM), sendo que a dimensão da educação é medida por meio de dois indicadores: a escolaridade da população adulta e o fluxo escolar da população jovem. Os indicadores aqui analisados estão em uma plataforma de consulta denominada Atlas Brasil $^{6}$ e são referentes aos dados do último Censo Demográfico (BRASIL, MEC/INEP, 2010).

Com base no IDHM e IDHM Educação apresenta-se os vinte municípios que implementaram o Programa BPC na Escola, demonstrados na tabela a seguir.

No Brasil, o IDHM aumentou 47,5\% entre 1991 a 2010 com redução das disparidades entre as regiōes Norte e Nordeste com as regiōes Sul, Sudeste e Centro-Oeste. No último censo demográfico (2010), o IDHM do Brasil foi considerado alto, com um índice de 0,727 (ATLAS BRASIL, 2013).

A dimensão de educação foi a que mais avançou nos últimos vinte anos no Brasil, com um acréscimo de $128,3 \%$. Porém, considerada com médio desenvolvimento $(0,637)$ em 2010 , foi a dimensão que menos contribuiu para o IDHM no país.

Dentre os municípios que apresentaram o IDHM baixo, destaca-se Nina Rodrigues (0,585), localizada no norte Maranhense, com 12.464 habitantes. 46,20\% de sua população são extremamente pobres e $66,30 \%$ vivem em situação de pobreza. A renda per capita do município é de R \$ 152,75 (ATLAS BRASIL, 2013). 
Deficiência e desigualdade social: o recente caminho para a escola

\section{Tabela 2}

IDHM e IDHM Educação dos vinte municípios

\begin{tabular}{|c|c|c|c|}
\hline Municípios (Estado) & Índice & IDHM & IDHM Educação \\
\hline Presidente Prudente (SP) & \multirow{3}{*}{ Muito alto } & 0,806 & 0,774 \\
\hline Santo André (SP) & & 0,815 & 0,769 \\
\hline São Paulo (SP) & & 0,805 & 0,725 \\
\hline Cuiabá (MT) & \multirow{7}{*}{ Alto } & 0,785 & 0,726 \\
\hline Nova Mutum (MT) & & 0,758 & 0,673 \\
\hline Goiânia (GO) & & 0,799 & 0,739 \\
\hline Campos dos Goytacazes (RJ) & & 0,716 & 0,619 \\
\hline Nova Iguaçu (RJ) & & 0,713 & 0,641 \\
\hline Novo Hamburgo (RS) & & 0,747 & 0,629 \\
\hline Porto Velho (RO) & & 0,736 & 0,638 \\
\hline Barro Alto (BA) & \multirow{4}{*}{ Médio } & 0,607 & 0,550 \\
\hline Piripiri (PI) & & 0,635 & 0,533 \\
\hline Itacajá (TO) & & 0,612 & 0,491 \\
\hline Campo Azul (MG) & & 0,621 & 0,546 \\
\hline Lapão (BA) & \multirow{6}{*}{ Baixo } & 0,596 & 0,510 \\
\hline Acopiara (CE) & & 0,595 & 0,517 \\
\hline Quiterianópolis (CE) & & 0,594 & 0,518 \\
\hline Nina Rodrigues (MA) & & 0,585 & 0,547 \\
\hline Pilóes (PB) & & 0,56 & 0,409 \\
\hline Frutuoso Gomes (RN) & & 0,597 & 0,512 \\
\hline
\end{tabular}

Fonte: Elaboração própria, com base nos dados censitários de 2010 do Atlas Brasil (2013).

O município de Pilóes também apresenta baixo IDHM $(0,560)$. Localizado no agreste paraibano, com 6.978 habitantes, o município apresentou o menor IDHM Educação $(0,409)$, sendo que apenas $27,10 \%$ da população de 18 anos ou mais possui o ensino fundamental completo. 
Com essa contextualização, apresenta-se a situação escolar dos beneficiários dos vinte municípios que implementaram o Programa BPC na Escola, segundo a área de moradia.

\section{Sobre a situação escolar e área de moradia dos beneficiários}

Os dados foram extraídos dos Relatórios ${ }^{7}$ elaborados a partir das visitas domiciliares aos beneficiários com deficiência, com idade entre 0 e 18 anos, cujo objetivo foi o de identificar as barreiras para acesso e permanência na escola. As visitas domiciliares foram realizadas no período de janeiro de 2009 a maio de 2010, no Distrito Federal e nos municípios que aderiram ao Programa BPC na escola em 2008.

Com o intuito de verificar a situação escolar dos beneficiários segundo a área de moradia (urbano/ rural), apresenta-se a Tabela 3.

O primeiro dado a se comentar é que a maioria dos beneficiários que vivem em área urbana dos municípios descritos na tabela está frequentando a escola. Entretanto, verifica-se que 28,2\% dos beneficiários que vivem em área urbana desses municípios já frequentaram a escola e não frequentam atualmente ou, ainda, nunca frequentaram.

Outro dado é que, nas áreas urbanas dos municípios localizados nas regiōes Norte e Nordeste, houve o maior percentual de beneficiários que nunca frequentaram a escola. Destacam-se Itacajá (TO), com 45,5\% dos beneficiários, e Lapão (BA), com 33,3\% dos beneficiários que nunca frequentaram a escola.

Constata-se que a situação escolar dos beneficiários que vivem em áreas rurais é ainda mais alarmante nas regiōes Norte e Nordeste. No município de Porto Velho (RO) foram registrados 7 beneficiários que vivem em áreas rurais; destes, 3 nunca frequentaram a escola e 1 beneficiário já frequentou a escola, mas atualmente não frequenta. Outro exemplo é o do município de Acopiara (CE), onde foi registrado um total de 51 beneficiários que vivem em áreas rurais; destes, 27 beneficiários nunca frequentaram a escola e 7 beneficiários já frequentaram a escola e não frequentam atualmente.

Um dos maiores desafios dos alunos que vivem no campo é o acesso à escola. Por conseguinte, verifica-se no Catálogo de Experiências Municipais do Programa BPC na Escola, com relatos de vinte municípios que 
Deficiência e desigualdade social: o recente caminho para a escola

\section{Tabela 3}

\begin{tabular}{|c|c|c|c|}
\hline \multirow[b]{2}{*}{ Municípios } & \multicolumn{3}{|c|}{ Beneficiário que vive na zona urbana } \\
\hline & $\begin{array}{l}\text { Frequenta a escola } \\
\text { atualmente }\end{array}$ & $\begin{array}{c}\text { Já frequentou } \\
\text { a escola e não frequenta } \\
\text { atualmente }\end{array}$ & $\begin{array}{l}\text { Nunca } \\
\text { frequentou a } \\
\text { escola }\end{array}$ \\
\hline Cuiabá (MT) & 382 & 78 & 47 \\
\hline Nova Mutum (MT) & 7 & 2 & 0 \\
\hline Goiânia (GO) & 622 & 63 & 43 \\
\hline Barro Alto (BA) & 1 & 0 & 0 \\
\hline Lapão (BA) & 3 & 1 & 2 \\
\hline Acopiara (CE) & 13 & 1 & 7 \\
\hline Quiterianópolis (CE) & 3 & 1 & 2 \\
\hline Nina Rodrigues (MA) & 11 & 4 & 2 \\
\hline Pilóes (PB) & 14 & 1 & 3 \\
\hline Piripiri (PI) & 76 & 33 & 18 \\
\hline Frutuoso Gomes (RN) & 3 & 2 & 0 \\
\hline Porto Velho (RO) & 238 & 50 & 55 \\
\hline Itacajá (TO) & 4 & 2 & 5 \\
\hline Novo Hamburgo (RS) & 131 & 9 & 2 \\
\hline Campo Azul (MG) & 0 & 0 & 1 \\
\hline Campos dos Goytacazes (RJ) & 218 & 15 & 15 \\
\hline Nova Iguaçu (RJ) & 264 & 53 & 48 \\
\hline Presidente Prudente (SP) & 99 & 12 & 5 \\
\hline Santo André (SP) & 322 & 12 & 19 \\
\hline São Paulo (SP) & 5031 & 1019 & 1294 \\
\hline
\end{tabular}

Fonte: Elaboração própria, com base nos relatórios divulgados no site: <http://bpcnaescola.mec.gov.br>. 
Situação escolar de beneficiários segundo a área de moradia

\begin{tabular}{|c|c|c|c|c|c|}
\hline \multirow[b]{2}{*}{ Total } & \multicolumn{4}{|c|}{ Beneficiário que vive na zona rural } & \multirow{2}{*}{$\begin{array}{c}\text { Total de } \\
\text { beneficiários }\end{array}$} \\
\hline & $\begin{array}{l}\text { Frequenta a escola } \\
\text { atualmente }\end{array}$ & $\begin{array}{l}\text { Já frequentou } \\
\text { a escola e não frequenta } \\
\text { atualmente }\end{array}$ & $\begin{array}{l}\text { Nunca } \\
\text { frequentou } \\
\text { a escola }\end{array}$ & Total & \\
\hline 507 & 3 & 0 & 2 & 5 & 512 \\
\hline 9 & 2 & 0 & 0 & 2 & 11 \\
\hline 728 & 1 & 0 & 0 & 1 & 729 \\
\hline 1 & 9 & 2 & 7 & 18 & 19 \\
\hline 6 & 4 & 2 & 2 & 8 & 14 \\
\hline 21 & 17 & 7 & 27 & 51 & 72 \\
\hline 6 & 23 & 8 & 6 & 37 & 43 \\
\hline 17 & 12 & 4 & 6 & 22 & 39 \\
\hline 18 & 7 & 2 & 3 & 12 & 30 \\
\hline 127 & 27 & 9 & 6 & 42 & 169 \\
\hline 5 & 5 & 2 & 0 & 7 & 12 \\
\hline 343 & 3 & 1 & 3 & 7 & 350 \\
\hline 11 & 3 & 0 & 2 & 5 & 16 \\
\hline 142 & 8 & 0 & 0 & 8 & 150 \\
\hline 1 & 1 & 0 & 2 & 3 & 4 \\
\hline 248 & 98 & 14 & 7 & 119 & 367 \\
\hline 365 & 13 & 5 & 2 & 20 & 385 \\
\hline 116 & 5 & 1 & 1 & 7 & 123 \\
\hline 353 & 5 & 0 & 0 & 5 & 358 \\
\hline 7344 & 124 & 26 & 27 & 177 & 7521 \\
\hline
\end{tabular}


implementaram o Programa, a presença de alunos beneficiários em áreas rurais. Em Itacajá (TO), o Grupo Gestor Local localizou beneficiários residentes nas zonas urbana, rural e na área indígena. No município de Barro Alto (BA), há um elevado índice de crianças que vivem na zona rural sem serviços de saúde. Em Acopiara (CE), a maioria dos beneficiários identificados vive na zona rural. Entretanto, como direito social, a Constituição Federal de 1988 assegura que o ensino escolar será ministrado em "igualdade de condições para o acesso e permanência na escola" (art. 206, $\$ \mathrm{I})$. Além disso, o Decreto n. 7.612 (2011), que institui o Plano Nacional dos Direitos da Pessoa com Deficiência - Plano Viver sem Limite, afirma, no artigo $3^{\circ}$, a "garantia de que os equipamentos públicos de educação sejam acessíveis para as pessoas com deficiência, inclusive por meio de transporte adequado".

O próximo passo é analisar o impacto do Programa BPC na Escola nos vinte municípios, baseando-se nas matrículas escolares.

\section{Sobre as matrículas escolares}

Os dados apresentados foram selecionados das informações divulgadas pelo Instituto Nacional de Estudos e Pesquisas Educacional Anísio Teixeira (Inep), do Ministério da Educação, por meio dos Censos Escolares de 2007 e 2012. A decisão pela escolha desse período se deu porque 2007 foi o ano da criação do Programa BPC na Escola (BRASIL, Portaria n. 8, 2007) e porque os dados mais atuais do Censo Escolar da Educação Básica são de 2012 (BRASIL, 2012).

Este trabalho focou o banco de dados de matrículas do censo escolar segundo as variáveis ${ }^{8}$ : necessidade educacional especial (NEE); ${ }^{9}$ tipo de deficiência (visual, auditiva, física, mental, síndrome de Down; ${ }^{10}$ deficiência múltipla $\left.{ }^{11}\right)$; idade (0-18 anos); municípios.

Com esse panorama em mãos, apresentam-se as matrículas de alunos com necessidades educacionais especiais (NEE), na idade de 0 a 18 anos, dos vinte municípios que implementaram o Programa BPC na escola e relataram suas experiências.

O primeiro dado a se comentar são os números reduzidos de matrículas de alunos com NEE, na faixa etária de 0 a 18 anos, no ano de 2007, nos municípios - destacam-se aqui os da Bahia e Maranhão. Vale relembrar que, no ano de 2007 , foi identificado no país que somente 
$21 \%$ dos beneficiários do BPC com deficiência, na faixa etária entre 0 e 18 anos, estavam na escola (BRASIL, 2013).

\section{Tabela 4}

Matrículas de alunos com NEE, de 0 a 18 anos de idade, segundo os municípios que aderiram ao BPC na escola

\begin{tabular}{|c|c|c|c|}
\hline \multirow{2}{*}{ Municípios } & \multicolumn{2}{|c|}{ Anos } & \multirow{2}{*}{$\begin{array}{l}\text { Variaçáo \% } \\
\text { no período }\end{array}$} \\
\hline & 2007 & 2012 & \\
\hline Cuiabá (MT) & 1003 & 2229 & 122,2 \\
\hline Nova Mutum (MT) & 53 & 127 & 139,6 \\
\hline Goiânia (GO) & 1998 & 6732 & 236,9 \\
\hline Barro Alto (BA) & 1 & 98 & 9700,0 \\
\hline Lapão (BA) & 1 & 55 & 5400,0 \\
\hline Acopiara (CE) & 83 & 130 & 56,6 \\
\hline Quiterianópolis (CE) & 36 & 125 & 247,2 \\
\hline Nina Rodrigues (MA) & 1 & 39 & 3800,0 \\
\hline Pilóes (PB) & 21 & 15 & $-28,6$ \\
\hline Piripiri (PI) & 265 & 413 & 55,8 \\
\hline Frutuoso Gomes (RN) & 8 & 10 & 25,0 \\
\hline Porto Velho (RO) & 633 & 2173 & 243,3 \\
\hline Itacajá (TO) & 8 & 24 & 200,0 \\
\hline Novo Hamburgo (RS) & 849 & 1391 & 63,8 \\
\hline Campo Azul (MG) & 7 & 9 & 28,6 \\
\hline Campos dos Goytacazes (RJ) & 776 & 1400 & 80,4 \\
\hline Nova Iguaçu (RJ) & 1120 & 2803 & 150,3 \\
\hline Presidente Prudente (SP) & 654 & 881 & 34,7 \\
\hline Santo André (SP) & 1226 & 2190 & 78,6 \\
\hline São Paulo (SP) & 24427 & 38252 & 56,6 \\
\hline
\end{tabular}

Fonte: Elaboração própria, com base nos microdados do Inep (2007a; 2012). 
Deficiência e desigualdade social: o recente caminho para a escola

\section{Tabela 5}

Matrículas de alunos com deficiência de 0 a 18 anos de idade, segundo os municípios que apresentaram o BPC na Escola

\begin{tabular}{|c|c|c|c|c|c|c|c|c|c|c|c|}
\hline \multirow{2}{*}{ Municípios } & \multicolumn{6}{|c|}{2007} & \multicolumn{5}{|c|}{2012} \\
\hline & DV & DA & DF & DM & SD & DMP & DV & DA & DF & DM & DMP \\
\hline Cuiabá (MT) & 61 & 221 & 63 & 371 & 72 & 292 & 156 & 257 & 409 & 1369 & 231 \\
\hline $\begin{array}{c}\text { Nova Mutum } \\
\text { (MT) }\end{array}$ & 7 & 5 & 8 & 13 & 5 & 19 & 9 & 14 & 24 & 90 & 9 \\
\hline Goiânia (GO) & 106 & 185 & 135 & 697 & 161 & 433 & 390 & 788 & 657 & 4847 & 481 \\
\hline Barro Alto (BA) & 0 & 1 & 0 & 0 & 0 & 0 & 31 & 4 & 8 & 56 & 5 \\
\hline Lapão (BA) & 0 & 0 & 0 & 0 & 0 & 0 & 17 & 3 & 11 & 20 & 2 \\
\hline Acopiara (CE) & 28 & 13 & 8 & 24 & 3 & 7 & 15 & 13 & 26 & 62 & 8 \\
\hline $\begin{array}{l}\text { Quiterianópolis } \\
\text { (CE) }\end{array}$ & 12 & 2 & 6 & 11 & 2 & 1 & 26 & 9 & 26 & 63 & 4 \\
\hline $\begin{array}{c}\text { Nina Rodrigues } \\
\text { (MA) }\end{array}$ & 0 & 0 & 0 & 0 & 0 & 0 & 7 & 4 & 11 & 19 & 3 \\
\hline Pilōes (PB) & 0 & 0 & 0 & 19 & 2 & 0 & 0 & 1 & 1 & 12 & 0 \\
\hline Piripiri (PI) & 8 & 33 & 7 & 126 & 15 & 58 & 42 & 38 & 79 & 249 & 57 \\
\hline $\begin{array}{c}\text { Frutuoso Gomes } \\
(\mathrm{RN})\end{array}$ & 0 & 4 & 1 & 4 & 0 & 0 & 0 & 2 & 2 & 5 & 0 \\
\hline Porto Velho (RO) & 37 & 131 & 61 & 199 & 89 & 48 & 271 & 276 & 343 & 1138 & 164 \\
\hline Itacajá (TO) & 0 & 1 & 1 & 6 & 0 & 0 & 4 & 4 & 3 & 15 & 2 \\
\hline $\begin{array}{c}\text { Novo Hamburgo } \\
\text { (RS) }\end{array}$ & 49 & 103 & 64 & 106 & 57 & 127 & 130 & 162 & 276 & 812 & 157 \\
\hline $\begin{array}{c}\text { Campo Azul } \\
\text { (MG) }\end{array}$ & 2 & 1 & 0 & 4 & 0 & 0 & 1 & 1 & 1 & 7 & 1 \\
\hline $\begin{array}{c}\text { Campos dos } \\
\text { Goytacazes (RJ) }\end{array}$ & 51 & 72 & 28 & 233 & 56 & 31 & 129 & 148 & 203 & 739 & 91 \\
\hline Nova Iguaçu (RJ) & 49 & 205 & 102 & 441 & 52 & 46 & 177 & 248 & 526 & 1774 & 165 \\
\hline $\begin{array}{c}\text { Presidente } \\
\text { Prudente (SP) }\end{array}$ & 53 & 47 & 54 & 252 & 48 & 89 & 95 & 95 & 186 & 531 & 110 \\
\hline Santo André (SP) & 126 & 127 & 189 & 544 & 57 & 56 & 193 & 228 & 475 & 1186 & 116 \\
\hline São Paulo (SP) & 2999 & 2633 & 3127 & 7329 & 3433 & 1417 & 2543 & 5053 & 6157 & 21182 & 785 \\
\hline
\end{tabular}

Fonte: Elaboração própria, com base nos microdados do Inep (2007a; 2012). 
Outro dado é que a maioria dos municípios que implementaram o Programa BPC na escola teve um aumento nas matrículas de alunos NEE, na faixa etária de 0 a 18 anos, no período analisado, o que indica a relevância do Programa. Entretanto, no município de Pilóes (PB), a tendência é de redução $(28,6 \%)$ no número de matrículas de alunos com NEE.

A Tabela 5 mostra as matrículas de alunos com deficiência (DA, DV, DF, DM, síndrome de Down - SD, deficiência múltipla - DMP) no período de 2007 e 2012, nos municípios aqui estudados.

As matrículas de alunos com deficiência visual apresentaram quedas em alguns municípios, entre eles Acopiara - CE (46,4\%), Campo Azul - MG (50\%) e São Paulo - SP (15,2\%). Porém, bem como ocorreu na maioria dos municípios, Goiânia - GO $(267,9 \%)$ e Porto Velho GO $(632,4 \%)$ apresentaram acréscimos nas matrículas de alunos com deficiência visual.

Nas matrículas de alunos com deficiência auditiva, com exceção do município de Frutuoso Gomes (RN), verificam-se acréscimos. As matrículas de alunos com deficiência física são representativas em todos os municípios. Além disso, apresentaram aumentos no período analisado. A maior concentração das matrículas de alunos com deficiência corresponde aos alunos com deficiência mental. Em 2012, as matrículas dessa deficiência predominavam nos vinte municípios. As matrículas de alunos com síndrome de Down são representativas nos municípios de São Paulo (SP) e Porto Velho (RO) e correspondem, respectivamente, a 16,4\% e 15,8\% das matrículas totais de alunos com deficiência.

Com relação às matrículas de alunos com deficiência múltipla, verifica-se que a maior parte dos municípios apresentou aumentos. Destacam-se os municípios de Nova Iguaçu - RJ (258,7\%) e Santo André - SP (107,1\%). Entretanto, ocorre outra tendência nas matrículas de alunos com deficiência múltipla nos municípios de Cuiabá - MT (20,9\%), Nova Mutum - MT (52,6\%) e Piripiri - PI (1,7\%), pois apresentaram reduções nas matrículas. Além disso, destaca-se o município de São Paulo (SP) com um decréscimo de 44,6\% nas matrículas de alunos com deficiência múltipla.

De modo geral, as matrículas de alunos com deficiência dos vinte municípios apresentaram aumentos no período, o que indica que a implementação do Programa BPC na Escola impactou no acesso à escola de pessoas com deficiência, na faixa etária de 0 a 18 anos. Entretanto, questiona-se 
Deficiência e desigualdade social: o recente caminho para a escola

sobre as condições de acesso e permanência na escola que os alunos com deficiência encontram. Essa realidade precisa ser conhecida, visando subsidiar a luta pelo direito à educação.

\section{Considerações finais}

A análise dos dados de matrículas nos municípios estudados revela que houve significativo aumento nas matrículas de alunos com necessidades educativas especiais, com destaque às matriculas de alunos com deficiência. Os vinte municípios estudados aderiram ao Programa BPC na Escola e divulgaram suas experiências sobre o trabalho de identificação de barreiras de acesso à educação regular. Os estudos nos permitem afirmar que os resultados são promissores em relação às matrículas.

Há ainda um exaustivo trabalho a ser realizado em prol da permanência desses alunos na escola e, acima de tudo, com a garantia da apropriação do conhecimento escolar. Nessa direção, a valorização do professor é questão fundamental. Formação inicial e continuada, salário digno e carreira docente são bases para oferecer melhores condições de trabalho aos profissionais da educação.

Portanto, para além das necessárias ações imediatas, vemos a urgência de pautarmos a discussão sobre qual é o projeto de sociedade, de educação e de educação especial que deve direcionar a produção do conhecimento e a tomada de decisões em políticas públicas. Tudo indica nesse estudo que foram removidas as primeiras barreiras que impediam os beneficiários de chegarem à escola. Daqui até sua participação social plena há um longo caminho, com o qual pesquisadores da área da educação especial podem muito contribuir, ao conhecerem as reais tramas históricas, sociais, políticas, econômicas e culturais que têm produzido a condição da deficiência e, acima de tudo, das desigualdades sociais em nosso país. Os resultados de pesquisa têm potência para subsidiar políticas públicas na área.

Os limites históricos devem ser tomados como desafios por pesquisadores, profissionais da educação e movimentos sociais comprometidos com a dignidade da vida humana.

\section{Notas}

1. Síntese de Indicadores Sociais: uma análise das condiçōes de vida dos brasileiros. Disponível em: <www.ibge.gov.br>. Acesso em: 15 jan. 2014. 
2. O Benefício de Prestação continuada da Assistência Social (BPC) foi instituído pela Constituição Federal de 1988 e regulamentado pela Lei Orgânica da Assistência Social (Loas), Lei n. 8.742, de 7/12/1993; pelas leis n. 12.435 , de 06/07/2011, e n. 12.470 , de 31/08/2011, que alteram dispositivos da Loas, e pelos decretos n. 6.214, de 26/09/2007, e n. 6.564, de 12/09/2008.

3. Sobre o Plano de Desenvolvimento da Educação (PDE), ver Saviani (2009).

4. Quanto mais perto de 1, mais alto é o desenvolvimento humano do país; quanto mais perto de 0 , mais baixo ele é.

5. Em 2011, a Noruega ocupou o $1^{\circ}$ lugar, com 0,955; Níger e Congo ocuparam a última posição, 186º com 0,304. Disponível em: <http://www.onu.org.br/>. Acesso em: 15 jan. 2014.

6. Disponível em: <http://www.atlasbrasil.org.br/>. Acesso em: 15 jan. 2014.

7. Relatórios divulgados no site: <www.bpcnaescola.mec.gov>. Acesso em: 13 jan. 2014.

8. As nomenclaturas das variáveis estão de acordo com o caderno de instruções do Inep. Disponível em: <http://portal.inep.gov.br/basica-levantamentos-microdados>. Acesso em: 9 jan. 2014.

9. Estudantes com deficiência, transtornos globais do desenvolvimento ou altas habilidades/superdotação (Caderno de Instruções, Inep).

10. A variável "síndrome de Down" está presente no censo escolar nos anos de 2007 e 2008.

11. Consiste na associação de dois ou mais tipos de deficiência (intelectual/visual/auditiva/física).

\section{Referências}

ATLAS BRASIL. Atlas do Desenvolvimento Humano no Brasil. [S.1]: PNUD, 2013. Disponível em: <http://atlasbrasil.org.br/>. Acesso em: 9 jan. 2014.

BRASIL. Decreto n. 6.949, de 25 de agosto de 2009. Promulga a Convenção Internacional sobre os Direitos das Pessoas com Deficiência e seu Protocolo Facultativo, assinados em Nova York, em 30 de março de 2007. Diário Oficial da União, Brasília, DF, 26 ago. 2009. Disponível em: <http://www4.planalto.gov.br/legislacao>. Acesso em: 18 jan. 2014.

BRASIL. Decreto n. 7.612, de 17 de novembro de 2011. Institui o Plano Nacional dos Direitos da Pessoa com Deficiência - Plano Viver sem Limite. Diário Oficial da União, Brasília, DF, 18 nov. 2011. Disponível em: <http://www.planalto.gov.br/ccivil_03/_Ato20112014/2011/Decreto/ D7612.htm>. Acesso em: 3 fev. 2014.

BRASIL. Grupo Gestor Interministerial. BPC na Escola: documento orientador. Brasília, DF: MEC, 2011. Disponível em: <portal.mec.gov.br>. Acesso em: 13 jan. 2014.

Disponível em <http://www.cedes.unicamp.br> 
Deficiência e desigualdade social: o recente caminho para a escola

BRASIL. Lei n. 8.742, de 7 de dezembro de 1993. Dispõe sobre a organização da Assistência Social e dá outras providências. Diário Oficial da União, Brasília, DF, 8 dez. 1993. Disponível em: <http://www4.planalto. gov.br/legislacao>. Acesso em: 18 jan. 2014.

BRASIL. Ministério da Educação. Instituto Nacional de Estudos e Pesquisas Educacionais Anísio Teixeira (INEP). Censo Escolar da Educação Básica - 2007. Brasília, DF: MEC/Inep, 2007. Disponível em: <http:// www.inep.gov.br/basica/levantamentos/microdados.asp $>$. Acesso em: 7 dez. 2013.

BRASIL. Ministério da Educação. Instituto Nacional de Estudos e Pesquisas Educacionais Anísio Teixeira (INEP). Censo Escolar da Educação Básica - 2008. Brasília, DF: MEC/Inep, 2008. Disponível em: <http://www.inep. gov.br/basica/levantamentos/microdados.asp>. Acesso em: 7 dez. 2013.

BRASIL. Ministério da Educação. Instituto Nacional de Estudos e Pesquisas Educacionais Anísio Teixeira (INEP). Censo Escolar da Educação Básica -2009. Brasília, DF: MEC/Inep, 2009. Disponível em: <http://www.inep. gov.br/basica/levantamentos/microdados.asp>. Acesso em: 8 dez. 2013.

BRASIL. Ministério da Educação. Instituto Nacional de Estudos e Pesquisas Educacionais Anísio Teixeira (INEP). Censo Escolar da Educação Básica - 2010. Brasília, DF: MEC/Inep, 2010. Disponível em: <http:// www.inep.gov.br/basica/levantamentos/microdados.asp $>$. Acesso em: 8 dez. 2013.

BRASIL. Ministério da Educação. Instituto Nacional de Estudos e Pesquisas Educacionais Anísio Teixeira (INEP). Censo Escolar da Educação Básica -2011. Brasília, DF: MEC/Inep, 2011. Disponível em: <http://www.inep. gov.br/basica/levantamentos/microdados.asp>. Acesso em: 9 dez. 2013.

BRASIL. Ministério da Educação. Instituto Nacional de Estudos e Pesquisas Educacionais Anísio Teixeira (INEP). Censo Escolar da Educação Básica -2012. Brasília, DF: MEC/Inep, 2012. Disponível em: <http://www.inep. gov.br/basica/levantamentos/microdados.asp> Acesso em: 10 dez. 2013.

BRASIL. Ministério da Educação. Secretaria de Educação Continuada, Alfabetização, Diversidade e Inclusão. Diretoria de Políticas de Educação Especial. Nota Técnica n. 13/2013, de 8 de fevereiro de 2013. Disponível em: <portal.mec.gov.br>. Acesso em: 13 jan. 2014. 
BRASIL. Ministério do Desenvolvimento Social e Combate à Fome (MDS). Catálogo de experiências municipais do Programa BPC na Escola. Brasília, DF: MDS, 2010.

BRASIL. Portaria Normativa Interministerial n. 18, de 24 de abril de 2007. Cria o Programa de Acompanhamento e Monitoramento do Acesso e Permanência na Escola das Pessoas com Deficiência Beneficiárias do Benefício de Prestação Continuada da Assistência Social. 2007. Disponível em: <http://www.mec.gov.br>. Acesso em: 18 jan. 2014.

CAIADO, K.R.M.; GONÇALVES, T.G.G.L. O transporte escolar público para os alunos do campo com necessidades educacionais especiais. Revista Teoria e Prática da Educação, Maringá. (No prelo).

CAIADO, K.R.M.; MELETTI, S.M.F. Educação especial na educação do campo: 20 anos de silêncio no GT 15. Revista Brasileira de Educação Especial, Marília, v. 17, p. 93-104, 2011.

JANNUZZI, G.M. A educação do deficiente no Brasil: dos primórdios ao início do século XXI. 3. ed. Campinas: Autores Associados, 2012.

JANNUZZI, G.M.; CAIADO, K.R.M. APAE: 1954 a 2011: algumas reflexões. Campinas: Autores Associados, 2013.

LANNA, M.C.M. História do movimento politico das pessoas com deficiência no Brasil. Brasília, DF: Secretaria Nacional de Promoção dos Direitos da Pessoa com Deficiência, 2010.

LOBO, L.F. Os infames da história: pobres, escravos e deficientes no Brasil. Rio de Janeiro: Lamparina, 2008.

MESTRINER, M.L. O estado entre a filantropia e a assistência social. 3. ed. São Paulo: Cortez, 2008.

ORGANIZAÇÃO DAS NAÇÕES UNIDAS (ONU), 2011. Disponível em: <http://onu.org.br/>. Acesso em: 9 jan. 2014.

PIERUCCI, A.F. Ciladas da diferença. São Paulo: Editora 34, 1999.

PASSO FUNDO. PREFEITURA. Orientaçôes para implementação da Política de Educação Especial na Perspectiva da Educação Inclusiva. Passo Fundo, [s.d.]. Disponível em: <http://www.pmpf.rs.gov.br/servicos/geral/ 
files/portal/Documento_Subsidiario_EducaCao_Especial.pdf $>$. Acesso em: 18 jan. 2014.

RAFANTE, H.C. Helena Antipoff, as Sociedades Pestalozzi e a educação especial no Brasil. 2011.319f. Tese (Doutorado em Educação) - Programa de Pós-Graduação em Educação, Universidade Federal de São Carlos. São Carlos.

SAVIANI, D. Plano de desenvolvimento da Educação: análise crítica da política do MEC. Campinas: Autores Associados, 2009.

SHIROMA, E.O.; MORAES, M.C.C.; EVANGELISTA, O. Politica educacional. 4. ed. Rio de Janeiro: Lamparina, 2007.

Recebido em fevereiro de 2014.

Aprovado em maio de 2014. 